\title{
The Impact of Red Blood Cell Distribution Width and Neutrophil/Lymphocyte Ratio on the Diagnosis of Major Depressive Disorder
}

Fatih Demircan · Nevzat Gözel · Faruk Kılınç · Ramazan Ulu •

Murat Atmaca

To view enhanced content go to www.neurologytherapy-open.com

Received: November 10, 2015 / Published online: December 19, 2015

(c) The Author(s) 2015. This article is published with open access at Springerlink.com

\section{ABSTRACT}

Introduction: Major depressive disorder (MDD) is an important risk factor for cardiovascular mortality and morbidity. Red blood cell distribution width (RDW) and neutrophil/lymphocyte ratio (NLR) can be obtained with a basic hemogram test. These parameters have been found as a predictor of mortality in the general population and in several diseases such as cardiovascular disease.

Methods: Our study included 100 patients with newly diagnosed MDD and 100 healthy control

F. Demircan $(\square)$

Department of Internal Medicine, Private Etic Life

Medical Center, Istanbul, Turkey

e-mail: drfdemircan@gmail.com;

fatihdemircan95@gmail.com

N. Gözel

Department of Internal Medicine, Firat Medical

Faculty, Elazig, Turkey

F. K1lınç

Department of Internal Medicine, Dicle University

Medical Faculty, Diyarbakir, Turkey

R. Ulu

Department of Nephrology, Firat Medical Faculty,

Elazig, Turkey

M. Atmaca

Department of Psychiatry, Firat Medical Faculty,

Elazig, Turkey patients (who had no depressive symptoms and without heart disease) admitted to our outpatient clinics. Patients with MDD were started on selective serotonin reuptake inhibitor (SSRI) treatment and followed up for 3 months. Both MDD and control patients' laboratory tests and physical, neurological, and psychiatric examinations were performed both at diagnosis and after 3 months of treatment.

Results: In total, 100 patients with MDD were evaluated and 80 were included in our study. The control group consisted of 91 healthy individuals. The mean age was $44 \pm 10.6$ years for patients with MDD and $39.8 \pm 11.4$ years for the control group. There was no significant difference between the age for groups $(P=0.13) ; 55 \%$ of patients with MDD and $33 \%$ of the control group was male. NLR levels were found to be $2.55 \pm 0.7$ and RDW levels were found to be $14.3 \pm 2.6$ in patients with MDD; NLR levels were found to be $1.41 \pm 0.8$ and RDW levels were found to be $13.4 \pm 1.8$ in the control group. RDW and NLR levels were significantly higher in patients with MDD compared to the control group. The significant difference between the levels of RDW and NLR 
in patients with MDD and the control group was dissolved after SSRI treatment $(P<0.001)$. RDW [median 14.3, interquartile range (IQR) 2.8 vs. median 13.25 , IQR $2.45 ; P<0.001]$ and NLR (median 2.3, IQR 1.1 vs. median 2.0, IQR $1.15 ; P<0.001)$ levels were significantly higher in patients with MDD compared to the control group.

Conclusion: Our study showed that hematological inflammatory markers might be useful parameters that can be used in patients with MDD for coronary artery disease risk. Specifically, RDW and NLR seem to be more hopeful. Advanced, detailed, and larger studies are needed.

Keywords: Coronary artery disease; Major depressive disorder; Mean platelet volume; Neutrophil/lymphocyte ratio; Red cell distribution width

\section{INTRODUCTION}

Major depressive disorder (MDD) is an important risk factor for cardiovascular morbidity and mortality [1, 2]. MDD increases cardiac mortality in both patients with cardiac disease and in healthy individuals [3]. The underlying physiopathological mechanism remains unclear. Several mechanisms have been affirmed such as smoking and physical inactivity $[4,5]$. Some traditional risks factors (hypertension, diabetes, and insulin resistance) and nontraditional risk factors (increased platelet reactivity, procoagulopathy, inflammation and dysregulation of the autonomic nervous system) for heart disease have also been reported [6].

Red cell blood distribution width (RDW) and neutrophil/lymphocyte ratio (NLR) can be obtained with a basic hemogram test. These parameters are cost effective, available, and simply calculated. RDW is a parameter that measures variation in red blood cell size or red blood cell volume. It is usually used for differential diagnosis of anemia, especially for iron deficiency anemia [7]. RDW has been shown to be a predictor of mortality in the general population [8] and in several diseases such as acute and chronic heart failure $[9,10]$, acute pulmonary embolism [11], myocardial infarction [12], peripheral arterial disease [13], and acute renal failure [14]. It has been shown that the rate of NLR gets higher as a response to systematic inflammation in stress. It has a prognostic importance in chronic inflammation such as cardiovascular disease, malignancies, ulcerative colitis, and hepatic cirrhosis $[15,16]$.

The relationship between plasma levels of RDW and NLR in patients with MDD has not yet been established. In this study, we aimed to investigate the relationship between these parameters and presence of MDD. Another objective was to evaluate the effect of selective serotonin reuptake inhibitor (SSRI) treatment on RDW and NLR levels in patients with MDD.

\section{METHODS}

\section{Patients}

Our study included 100 patients with newly diagnosed MDD and 100 control patients admitted to our outpatient clinics for routine examination. Control patients consisted of people who did not meet the exclusion criteria and without depressive symptoms. Control group age and gender characteristics were closed. We followed up with these patients from August to November 2014. Patients were evaluated both at diagnosis and after 3 months 
of treatment. All patients signed consent forms to participate in this study. The study protocol was approved by the ethics committee of Firat University, Faculty of Medicine, Elazig, Turkey. The study was conducted in accordance with the Declaration of Helsinki.

\section{Clinical Examination}

All patients were questioned for medical history. Physical, neurological, and psychiatric examinations were done, and laboratory test was performed for both patients with MDD and healthy control individuals at first diagnosis and after 3 months of treatment.

\section{Biochemical Measurements}

Fasting venous blood samples were collected in the morning after $8 \mathrm{~h}$ of fasting. The assays were performed at the laboratory in Cagri Private Medical Center and Firat University's Faculty of Medicine using a biochemical analyzer (ABX Pentra DX 120; HORIBA, Ltd.). Hemograms were determined with an autoanalyzer (Coulter $^{\circledR} \quad$ LH 780 hematology system; Beckman Coulter, Inc.). The blood samples were processed within $30 \mathrm{~min}$ after blood collection. Baseline NLR was measured by dividing absolute neutrophil count by absolute lymphocyte count.

\section{Diagnosis and Exclusion Criteria}

The Diagnostic and Statistical Manual of Mental Disorders, 4th Edition's (DSM-IV) criteria were used for diagnosing MDD. The Montgomery-Åsberg Depression Rating Scale (MADRS) [17] was used for assessing the severity of depression and the effectiveness of the treatment. Patients with cardiovascular disease, hepatic or renal failure, previously detected malignancies, diabetes mellitus, hyperthyroidism, pregnancy, chronic obstructive pulmonary disease, or who were smokers or using anticoagulant-antiplatelet medications were excluded from the study. Hemoglobin $<13 \mathrm{~g} / \mathrm{dL}$ for males and $<12 \mathrm{~g} / \mathrm{dL}$ for females, and white blood cell counts $>12,000$ cells and $<4000$ cells were ignored. Laboratory tests were repeated after 3 months.

\section{Treatment}

Patients with MDD were treated with SSRIs (escitalopram and sertraline) for 3 months. Escitalopram was dosed from 10 to $20 \mathrm{mg}$ /day and sertraline was dosed from 25 to $100 \mathrm{mg} /$ day.

\section{Statistical Analysis}

All statistical analyses were performed with the SPSS version 15.0 (SPSS Inc., Chicago, IL, USA). The significance of the mean differences between groups was assessed by Student's $t$ test. Also, paired $t$ test was used for repeated data in the patient group. Data were presented as mean \pm standard deviation. Relationships between variables were tested using Pearson's correlation analysis. Receiver operating characteristic (ROC) curve graphics were used in the comparison of sensitivity and specificity. $P$ values less than 0.05 were regarded as significant.

\section{RESULTS}

A total of 100 patients with MDD were evaluated and 80 patients were included in the study. The control group consisted of 91 healthy individuals. Mean age was $44 \pm 10.6$ years in patients with MDD and 
$39.8 \pm 11.4$ years in the healthy control group. There was no significant difference between the mean age of the groups $(P=0.13) ; 55 \%$ of patients with MDD and $53.8 \%$ of the healthy control group were male. The demographic and gender distributions of the subjects are summarized in Table 1.

NLR levels were found to be $2.55 \pm 0.7$ and RDW levels were found to be $14.3 \pm 2.6$ in patients with MDD; NLR levels were found to be $1.41 \pm 0.8$ and RDW levels were found $13.4 \pm 1.8$ in the control group. RDW and NLR levels were significantly higher in patients with MDD compared to the control group. The significant difference between the levels of RDW and NLR in patients with MDD and the control group was dissolved after SSRI treatment $(P<0.001)$. Baseline RDW levels and NLR of the groups are shown in Table 2.

RDW [median 14.3, interquartile range (IQR) 2.8 vs. median 13.25 , IQR $2.45 ; P<0.001]$ and NLR (median 2.3 IQR 1.1 vs. median 2.0, IQR $1.15 ; P<0.001)$ levels were significantly higher in patients with MDD compared to the control group. ROC analysis revealed that an RDW measurement higher than $95 \%$ predicted depression with a sensitivity of $60 \%$ and a specificity of $58 \%$ in the study population (area under the curve $0.62, P=0.007$ ). The cutoff value for NLR for diagnosis of MDD in the study population was 2.05 (Fig. 1).

In patients with MDD, platelet counts were $186.6 \pm 66 \times 10^{9} / \mathrm{L}$ and mean platelet volume (MPV) levels were $10.3 \pm 1.5 \mathrm{fl}$. In the control group, platelet counts were $190.1 \pm 69.7 \times 10^{9} / \mathrm{L}$ and MPV levels were $9.6 \pm 1.2 \mathrm{fl}$. MPV levels were significantly higher in MDD group $(P<0.001)$ and significantly decreased after SSRI treatment when compared to the basal level $(P<0.001)$. The platelet counts were lower in patients with MDD as compared to the
Table 1 The demographic and gender distributions of the patients with MDD and the healthy control group

\begin{tabular}{llll}
\hline & $\begin{array}{l}\text { Patients with } \\
\text { MDD }\end{array}$ & Controls & P value \\
\hline $\begin{array}{l}\text { Number of } \\
\text { patients }\end{array}$ & 80 & 91 & \\
Age (years) & $44.10 \pm 10.60$ & $39.80 \pm 11.50$ & 0.013 \\
Male $(n / \%)$ & $44 / 55 \%$ & $49 / 53.8 \%$ & 0.004 \\
Female $(n / \%)$ & $36 / 45 \%$ & $42 / 46.2 \%$ & 0.004 \\
\hline
\end{tabular}

$M D D$ major depressive disorder

control group, but the difference was not significant $\quad(P=0.17)$. No significant difference was observed in platelet counts after treatment. The parameters are reported in Table 3.

The significant differences between the levels of RDW, MPV, and NLR in the MDD and control groups were dissolved after the SSRI treatment $(P<0.001)$. The effects of treatment on laboratory parameters in patients with MDD are given in Table 3 .

\section{DISCUSSION}

Patients with MDD are at an increased risk for cardiovascular disease $[1,2]$. The underlying mechanism is not clearly known. Multiple mechanisms are involved in the relationship between MDD and ischemic cardiac disease.

There is no serum marker for the diagnosis of depression. An increased RDW level is expected in inflammatory and infectious pathologies due to release of premature reticulocytes into the circulation. On the contrary, Narci et al. [18] found lower RDW levels in patients with acute appendicitis compared to controls. They suggested this finding may be the result of greater RDW levels in chronic inflammatory diseases compared to that in acute conditions [18]. 
Table 2 Baseline RDW levels and NLR of the study groups

\begin{tabular}{lccc}
\hline & Patients with MDD $(\boldsymbol{n}=\mathbf{8 0})$ & Control group $(\boldsymbol{n}=\mathbf{9 1})$ & $\boldsymbol{P}$ value \\
\hline NLR & $2.55 \pm 0.70$ & $1.41 \pm 0.8$ & $<0.001$ \\
RDW & $14.30 \pm 2.60$ & $13.30 \pm 1.2$ & 0.001 \\
$\operatorname{PLT}\left(\times 10^{9} / \mathrm{L}\right)$ & $186.60 \pm 66.10$ & $190.10 \pm 69.7$ & 0.53 \\
MPV $(\mathrm{f})$ & $10.30 \pm 1.50$ & $9.10 \pm 1.2$ & $<0.001$ \\
\hline
\end{tabular}

$M D D$ major depressive disorder, MPV mean platelet volume, $N L R$ neutrophil/lymphocyte ratio, $P L T$ platelet, $R D W$ red blood cell distribution width

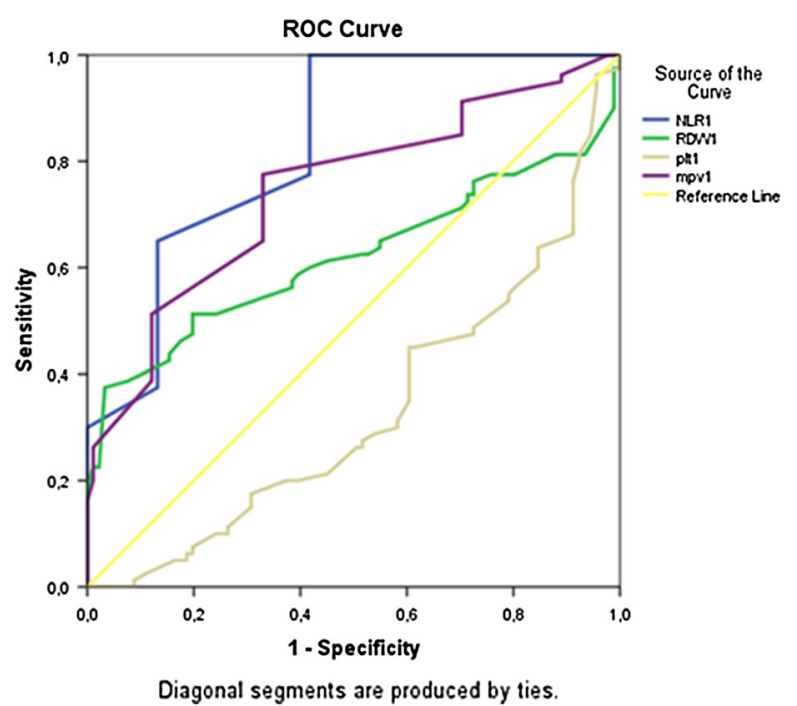

Fig. 1 Curve of NLR, RDW, PLT, and MPV levels in patients with major depressive disorder. Diagonal segments are produced by ties. $M P V$ mean platelet volume, NLR neutrophil/lymphocyte ratio, PLT platelet, $R D W$ red blood cell distribution width, $R O C$ receiver operating characteristic
Lymphocytes play a major role in chronic inflammation. Lymphocytes infiltrating the ischemic and re-perfused tissue and may have a significant role in healing. The relative lymphopenia observed in patients with acute ischemia is considered to be a stress response as a result of increased endogenous cortisol [19].

NLR is a hematologic parameter that is studied the most. Like other hematological inflammatory markers, most studies focus on its prognostic power. It was found to be a simple, readily available, inexpensive, and independent predictor marker for various cardiovascular diseases, such as stable coronary artery disease, acute coronary syndromes, and heart failure [20].

Previous studies demonstrate that serotonin affects immunological response like inflammation by affecting proliferation of lymphocyte [21, 22]. NLR significantly

Table 3 Before and after treatment levels of RDW and NLR in patients with major depressive disorder

\begin{tabular}{lccr}
\hline & Before treatment & After treatment & P value \\
\hline NLR & $2.55 \pm 0.70$ & $2.03 \pm 0.7$ & $<0.001$ \\
RDW & $14.30 \pm 2.60$ & $13.40 \pm 1.8$ & $<0.001$ \\
PLT $\left(\times 10^{9} / \mathrm{L}\right)$ & $186.60 \pm 66.10$ & $190.10 \pm 69.7$ & 0.71 \\
$\operatorname{MPV}(\mathrm{fl})$ & $10.30 \pm 1.50$ & $9.60 \pm 1.2$ & $<0.001$ \\
\hline
\end{tabular}

$M P V$ mean platelet volume, NLR neutrophil/lymphocyte ratio, $P L T$ platelet, $R D W$ red blood cell distribution width 
decreasing after SSRI treatment in our study also supported this hypothesis.

As far as we know, our study is the first case-control study that assesses the diagnostic capability of hematologic inflammatory markers to define depression. We showed that hematological inflammatory markers' levels like RDW levels and NLR are found to be higher in patients with MDD than healthy controls, and maybe a valuable tool for the discrimination.

Decreasing levels of RDW and NLR after SSRI treatment suggests that these medications may have an anti-inflammatory effect.

In conclusion, our study showed that hematological inflammatory markers might be useful parameters that can be used in MDD patients for coronary artery disease risk; especially RDW and NLR seems to be more hopeful. Advanced, detailed and larger studies are needed.

\section{Limitations}

The present study has several limitations. For instance, the sample size was not calculated before enrolling participants in the study. Other SSRI drugs could be studied and patients could be divided into two groups, one using escitalopram and another using sertraline. Body mass index, blood pressure, and biological markers were not compared with the severity of depression.

\section{ACKNOWLEDGMENTS}

No funding or sponsorship was received for this study or publication of this article. All named authors meet the International Committee of Medical Journal Editors (ICMJE) criteria for authorship for this manuscript, take responsibility for the integrity of the work as a whole, and have given final approval for the version to be published.

Disclosures. Fatih Demircan, Nevzat Gözel, Faruk Kılınç, Ramazan Ulu, and Murat Atmaca have nothing to disclose.

Compliance with Ethics Guidelines. All patients signed consent forms to participate in this study. The study protocol was approved by the ethics committee of Firat University, Faculty of Medicine, Elazig, Turkey. The study was conducted in accordance with the Declaration of Helsinki.

Open Access. This article is distributed under the terms of the Creative Commons Attribution-NonCommercial 4.0 International License (http://creativecommons.org/licenses/ by-nc/4.0/), which permits any noncommercial use, distribution, and reproduction in any medium, provided you give appropriate credit to the original author(s) and the source, provide a link to the Creative Commons license, and indicate if changes were made.

\section{REFERENCES}

1. Frasure-Smith N, Lespérance F, Talajic $M$. Depression following myocardial infarction. Impact on 6-month survival. JAMA. 1993;270:1819-25.

2. Bush DE, Ziegelstein RC, Tayback M, Richter D, Stevens S, Zahalsky H, Fauerbach JA. Even minimal symptoms of depression increase mortality risk after acute myocardial infarction. Am J Cardiol. 2001;88:337-41.

3. Penninx BW, Beekman AT, Honig A, Deeg DJ, Schoevers RA, van Eijk JT, van Tilburg W. Depression and cardiac mortality: results from a community-based longitudinal study. Arch Gen Psychiatry. 2001;58:221-7.

4. Parissis JT, Fountoulaki K, Filippatos G, Adamopoulos S, Paraskevaidis I, Kremastinos D. 
Depression in coronary artery disease: novel pathophysiologic mechanisms and therapeutic implications. Int J Cardiol. 2007;116:153-60.

5. Nemeroff CB, Musselman DL. Are platelets the link between depression and ischemic heart disease? Am Heart J. 2000;140:57-62.

6. Markovitz JH, Matthews KA. Platelets and coronary heart disease: potential psychophysiologic mechanisms. Psychosom Med. 1991;53:643-68.

7. Morgan DL, Peck SD. The use of red cell distribution width in the detection of iron deficiency in chronic hemodialysis patients. Am J Clin Pathol. 1988;89(4):513-5.

8. Zalawadiya SK, Veeranna V, Panaich SS, Afonso L, Ghali JK. Gender and ethnic differences in red cell distribution width and its association with mortality among low risk healthy United State adults. Am J Cardiol. 2012;109(11):1664-70.

9. van Kimmenade RRJ, Mohammed AA, Uthamalingam S, Van DerMeer P, Felker GM, Januzzi JL Jr. Red blood cell distribution width and 1-year mortality in acute heart failure. Eur J Heart Fail. 2010;12(2):129-36.

10. Al-Najjar Y, Goode KM, Zhang J, Cleland JGF, Clark AL. Red cell distribution width: an inexpensive and powerful prognostic marker in heart failure. Eur J Heart Fail. 2009;11(12):1155-62.

11. Zorlu A, Bektasoglu G, Guven FMK, et al. Usefulness of admission red cell distribution width as a predictor of early mortality in patients with acute pulmonary embolism. Am J Cardiol. 2012;109(1):128-34.

12. Azab B, Torbey E, Hatoum H, et al. Usefulness of red cell distribution width in predicting all-cause long-term mortality after non-ST-elevation myocardial infarction. Cardiology. 2011;119(2):72-80.

13. Ye Z, Smith C, Kullo IJ. Usefulness of red cell distribution width to predict mortality in patients with peripheral artery disease. Am J Cardiol. 2011;107(8):1241-5.
14. Oh HJ, Park JT, Kim J-K, et al. Red blood cell distribution width is an independent predictor of mortality in acute kidney injury patients treated with continuous renal replacement therapy. Nephrol Dial Transplant. 2012;27(2):589-94.

15. Tasoglu I, Sert D, Colak $\mathrm{N}$ et al. Neutrophil-lymphocyte ratio and the platelet-lymphocyte ratio predict the limb survival in critical limb ischemia. Clin Appl Thromb/ Hemostasis. (In press).

16. Biyik M, Ucar R, Solak $\mathrm{Y}$, et al. Blood neutrophil-to-lymphocyte ratio independently predicts survival in patients with liver cirrhosis. Eur J Gastroenterol Hepatol. 2013;25:435-41.

17. Montgomery SA, Asberg M. A new depression scale designed to be sensitive to change. Br J Psychiatry. 1979;134:382-9.

18. Narci H, Turk E, Karagulle E, Togan T, Karabulut K. The role of red cell distribution width in the diagnosis of acute appendicitis: a retrospective case controlled study. World J Emerg Surg. 2013;8:46-51.

19. Ommen SR, Gibbons RJ, Hodge DO, Thomson SP. Usefulness of the lymphocyte concentration as a prognostic marker in coronary artery disease. Am J Cardiol. 1997;79:812.

20. Bhat T, Teli S, Rijal J, Bhat H, Raza M, Khoueiry G, et al. Neutrophil to lymphocyte ratio and cardiovascular diseases: a review. Expert Rev Cardiovasc Ther. 2013;11:55-9.

21. Kut JL, Young MR, Crayton JW, Wright MA, Young ME. Regulation of murine T-lymphocyte function by spleen cell-derived and exogenous serotonin. Immunopharmacol 1992;14(4):783-96. Immunotoxicol.

22. Young MR, Kut JL, Coogan MP, Wright MA, Young ME, Matthews J. Stimulation of splenic T-lymphocyte function by endogenous serotonin and by low-dose exogenous serotonin. Immunology. 1993;80(3):395-400. 